\title{
Plastic zone evolution near a crack tip and its role in environmentally assisted cracking
}

\author{
Jesús Toribio, Viktor Kharin \\ University of Salamanca, Spain
}

\begin{abstract}
This paper analyzes the effects of crack tip plastic strains and compressive residual stresses, created by fatigue pre-cracking, on environmentally assisted cracking of pearlitic steel subjected to localized anodic dissolution and hydrogen assisted fracture. In both situations, cyclic crack tip plasticity improves the behavior of the steel. In the respective cases, the effects are supposed to be due to accelerated local anodic dissolution of the cyclic plastic zone (producing chemical crack blunting) or to the delay of hydrogen entry into the metal caused by residual compressive stresses, thus increasing the fracture load in aggressive environment.
\end{abstract}

KEYWORDS. Plastic zone; Near-tip stress-strain fields; Environmentally assisted cracking.

\section{INTRODUCTION}

$\mathrm{E}$ nvironmentally assisted cracking (EAC) of metals is usually evaluated by testing of pre-cracked specimens prepared by fatigue (cyclic) loading in laboratory air that produces a redistribution of stresses and strains as a consequence of cyclic plastic deformations. Compressive residual stresses generated at fatigue load release, together with plastic strains, affect the stress corrosion behavior of materials [1].

This paper deals with the mechanical effects of pre-loading on the posterior EAC in a pearlitic high-strength steel wire used for prestressed concrete structures. The rising load EAC experiments are considered in combination with numerical modeling of the elastoplastic stress-strain field near the crack tip subjected to fatigue pre-cracking and subsequent monotonic loading during EAC tests.

\section{EXPERIMENTAL}

$\mathrm{E}$ AC experiments were performed with a series of $\mathrm{K}_{\max } / \mathrm{K}_{\mathrm{IC}}=0.28,0.45,0.60$ and 0.80 , where $\mathrm{K}_{\mathrm{IC}}$ is the fracture toughness of the material and $\mathrm{K}_{\max }$ the maximum stress intensity factor during fatigue precracking. The experiments were rising load tests of pre-cracked specimens in aqueous solution under anodic and cathodic potentials to evaluate the two main mechanisms of EAC [2]: localized anodic dissolution (LAD) under the anodic regime and hydrogen assisted cracking (HAC) under the cathodic regime. The full experimental details are described elsewhere [1].

The tested high-strength steel has the properties given in Tab. 1. For the two regimes of environmental cracking (HAC and LAD), Fig. 1 plots the failure load during the EAC test (evaluated through the ratio of the failure load in aggressive environment $\mathrm{F}_{\mathrm{EAC}}$ to the failure load in air $\mathrm{F}_{\mathrm{C}}$ ) as a function of the severity of the fatigue precracking regime (expressed in dimensionless terms as the maximum stress intensity factor during fatigue precracking $\mathrm{K}_{\max }$ divided by the fracture toughness of the material $\mathrm{K}_{\mathrm{IC}}$ ). For both LAD and HAC, heavier pre-cracking is beneficial for the EAC resistance of the steel. This may be attributed to the cyclic plastic zones and compressive stresses near the crack tip due to fatigue. The 
higher the cyclic load level, the stronger the pre-straining/stressing effect which delays environmental damage (metal dissolution in LAD or hydrogen entry in HAC) and improves material performance in a hostile environment.

\begin{tabular}{|c|c|c|c|c|c|c|}
\hline \multirow{3}{*}{$\begin{array}{l}\text { Young } \\
\text { modulus } \\
\text { E [GPa] }\end{array}$} & \multirow{3}{*}{$\begin{array}{c}\text { Tensile Yield } \\
\text { Strength } \sigma_{\mathrm{Y}} \\
\text { [MPa] }\end{array}$} & \multirow{3}{*}{$\begin{array}{c}\text { Toughness } \\
\mathrm{K}_{\mathrm{IC}} \\
{[\mathrm{MPa} \sqrt{\mathrm{m}}]}\end{array}$} & \multicolumn{4}{|c|}{ Ramberg-Osgood curve $\varepsilon=\sigma / \mathrm{E}+(\sigma / \mathrm{P})^{\mathrm{n}}$} \\
\hline & & & \multicolumn{2}{|c|}{ (I) $\varepsilon^{\mathrm{P}}<1.07$} & \multicolumn{2}{|c|}{ (II) $\varepsilon^{\mathrm{P}}>1.07$} \\
\hline & & & $\mathrm{P}_{\mathrm{I}}(\mathrm{MPa})$ & $\mathrm{n}_{\mathrm{I}}$ & $\mathrm{P}_{\mathrm{II}}(\mathrm{MPa})$ & $\mathrm{n}_{\mathrm{II}}$ \\
\hline 195 & 725 & 53 & 2120 & 5.8 & 2160 & 17 \\
\hline
\end{tabular}

Table 1: Mechanical properties of the steel.

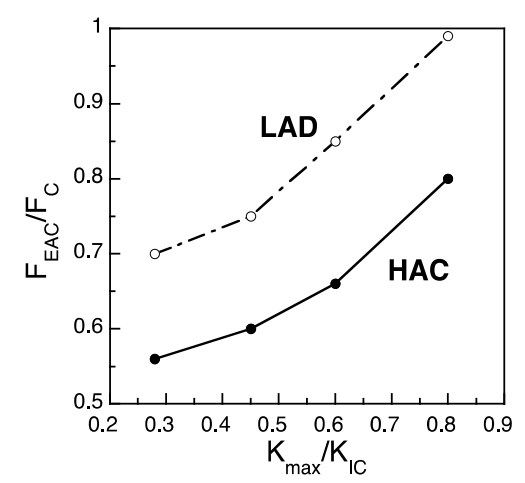

Figure 1: Failure load during the EAC test as a function of the severity of the fatigue precraking regime.

Fractographic analysis of the samples after HAC tests revealed the existence of a particular microscopic fracture mode (Fig. 2a) which is a signal of hydrogen assisted microdamage [3] in pearlitic steels as those used in the present work: the so called tearing topography surface (TTS) between the fatigue pre-crack and the final cleavage fracture. Measured TTS depth $\mathrm{x}_{\text {TTS }}$ also depends on the pre-cracking regime, as plotted in Fig. 2b. Again this may be attributed to the cyclic plastic zones and compressive stresses near the crack tip due to fatigue.

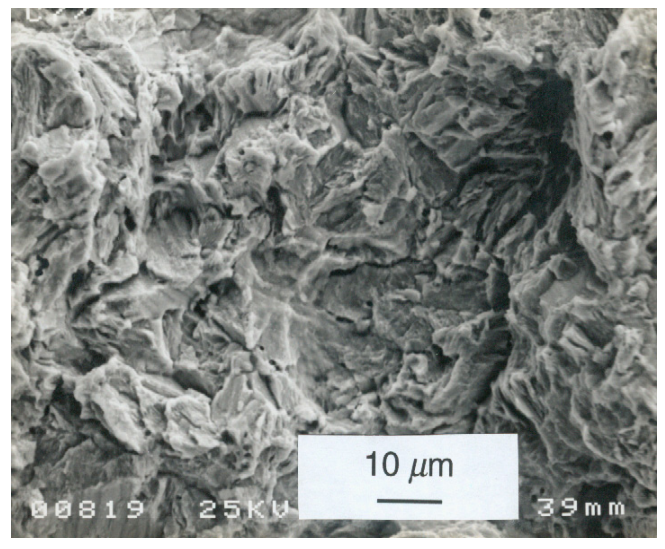

(a)

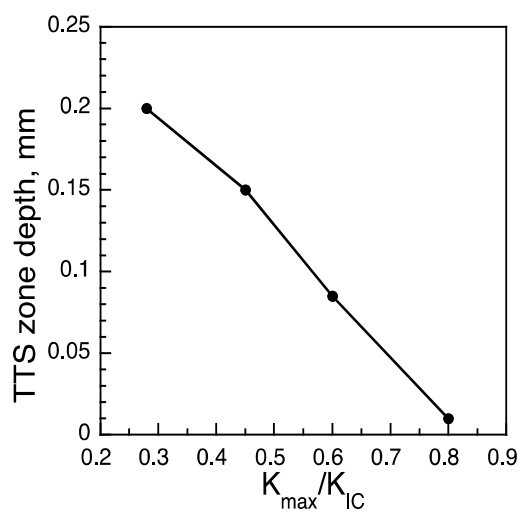

(b)

Figure 2: (a) Fractographic appearance of the Tearing Topography Surface (TTS), (b) Depth of the TTS zone in the HAC tests (cathodic regime of $\mathrm{EAC})$ as a function of the severity of the fatigue precraking regime $\left(\mathrm{K}_{\max } / \mathrm{K}_{\mathrm{IC}}\right)$.

\section{MODELLING OF CRACK TIP MECHANICS}

$\mathrm{T}$

o ascertain the effects of pre-cracking on EAC, the evolutions of mechanical variables associated with EAC are desired. In previous analyses [4] the Rice model [5] was applied. In this paper, a high-resolution numerical modelling of the crack tip stresses and strains during fatigue pre-cracking and rising load EAC test was performed 
for an elastoplastic material with von Mises yield surface and Ramberg-Osgood strain-hardening rule. Mixed isotropickinematic hardening was used to capture Bauschinger-type effects. Model parameters corresponded to the steel used in the experiments (Tab. 1).

Finite deformation analysis of a plane strain crack under mode I (opening) load was confined to small scale yielding, so that the stress intensity factor $\mathrm{K}$ is the only variable governing the near tip mechanics [6]. The initial crack was modeled as a parallel-sided round-tip slit with initial height $b_{0}=5 \mu \mathrm{m}$ in agreement with data for fatigue cracks in steels [7]. Simulated loading histories consisted of several zero-to-tension cycles with $\mathrm{K}_{\max } / \mathrm{K}_{\mathrm{IC}}=0.45,0.60$ and 0.80 , followed by rising load representing the EAC tests. An updated Lagrangian formulation was used in the computations.

Plastic zones developed fairly self-similar with a scaling factor of $\left(\mathrm{K} / \sigma_{\mathrm{Y}}\right)^{2}$, which is natural for the K-dominated crack-tip domain and coincides with the prediction by Rice [5]. At loading up to the first load reversal at $\mathrm{K}_{\max }$, the monotonic plastic zone is defined by the equivalent von Mises stress $\sigma_{\mathrm{eq}}=\sigma_{\mathrm{Y}}$ (Fig. 1, left) where $\sigma_{\mathrm{Y}}$ is the tensile yield stress.

Because of strain hardening, after load reversal the $\sigma_{Y^{-}}$stress based yield criterion must not indicate further where plastic flow really proceeds. The cyclic plastic zones are defined then by positive equivalent plastic strain rate, $\xi_{\text {eq }}{ }^{\mathrm{p}}>0$ (Fig. 1 , right). They are approximately the same at cyclic load minima (reversed zones at $\mathrm{K}_{\min }=0$ ) and maxima (forward zones at $\mathrm{K}_{\mathrm{max}}$ ), smaller than the monotonic zone and quite stable with the cycle number.

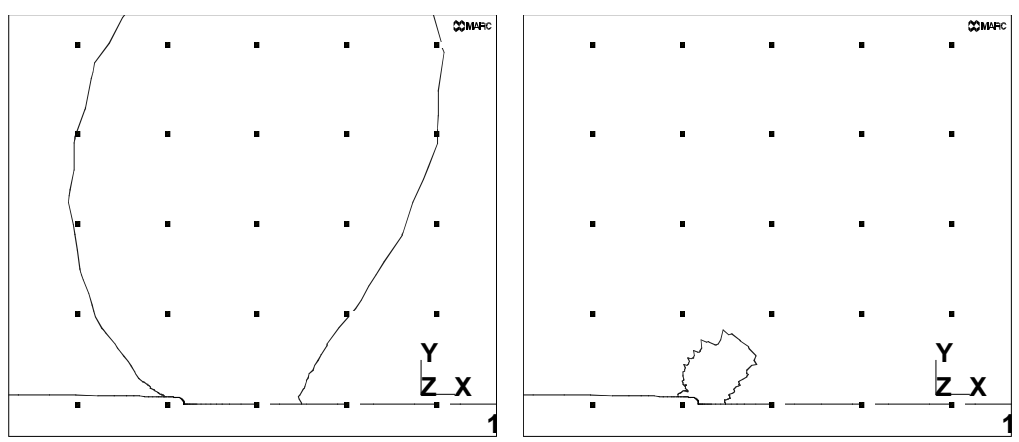

Figure 3: Monotonic (left) and cyclic (right) plastic zones at $\mathrm{K}=\mathrm{K}_{\max }$ for $\mathrm{K}_{\max } / \mathrm{K}_{\mathrm{IC}}=0.6$ (the grid spacing is $50 \mu \mathrm{m}$ ).

At rising load, plastic flow starts at $\mathrm{K}=0.2 \mathrm{~K}_{\max }$ after elastic reloading and develops identically as the cyclic zone does up to attaining the pre-cracking level of $\mathrm{K}=\mathrm{K}_{\max }$, when it bursts and advances as the monotonic plastic zone does.

The near tip stress distributions differ substantially from estimation given by Rice [5]. They stabilize after few first cycles as soon as a steady state of alternating plastic flow is approached. Fig. 4 shows the evolution of the hydrostatic stress in the crack plane beyond the tip, $\sigma=\sigma(\mathrm{x})$, where $\mathrm{x}$ is the distance to the crack tip in the deformed configuration of a solid, during monotonic loading in the EAC test after pre-cracking. This stress component is focused since it is determinant for HAC controlled by stress-assisted hydrogen diffusion driven by the gradient $\nabla \sigma$ towards maximum stress locations [8, 9].
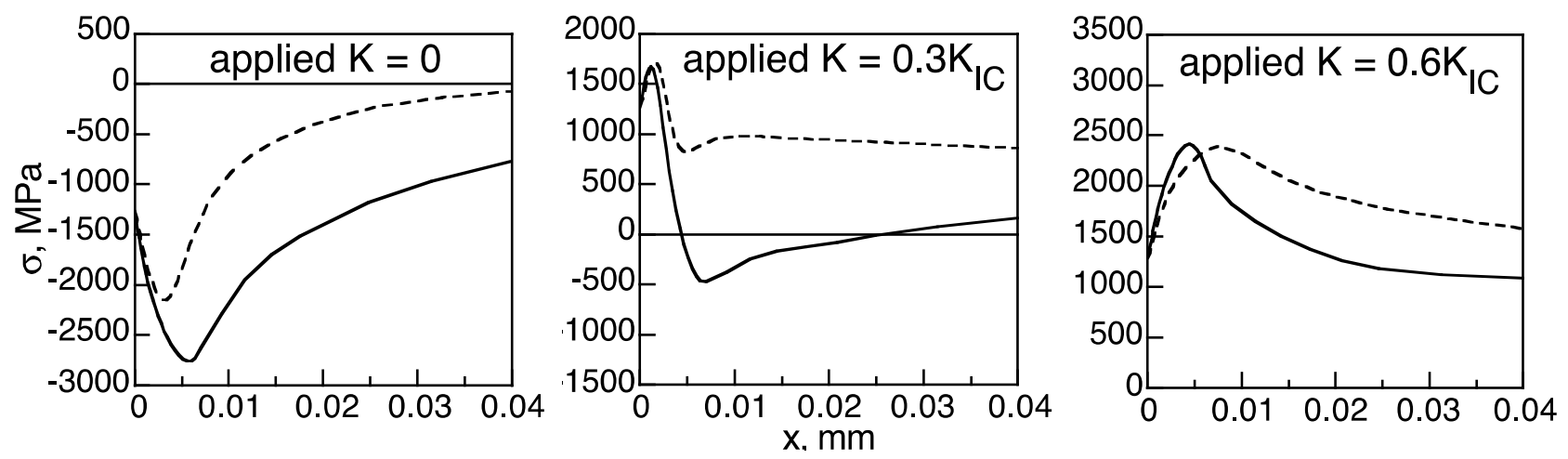

Figure 4: Hydrostatic stress distributions beyond the crack tip during monotonic loading at EAC test after fatigue pre-cracking at $\mathrm{K}_{\text {max }} / \mathrm{K}_{\mathrm{IC}}=0.45$ (dashed lines) and 0.80 (solid lines). 


\section{Discussion}

10 analyze the results of the EAC tests on the basis of crack tip mechanics, the critical stress intensity factor for $E A C$ to proceed $K_{\text {QEAC }}$ is evaluated from the experimental failure loads (Fig. 1) as $K_{\text {QEAC }}=\left(F_{E A C} / F_{C}\right.$ ) $K_{I C}$ (air).

For $L A D$-controlled fracture, fatigue pre-cracking may cause a strong protective effect characterized by the fracture loads ratio $\mathrm{F}_{\mathrm{EAC}} / \mathrm{F}_{\mathrm{C}}$ (Fig. 1). Considering mechanical factors of $\mathrm{EAC}$, the normal stresses at the crack tip surface $($ at $\mathrm{x}=$ $0)$ and the crack tip plastic strains may influence LAD processes [2]. Evolutions of the crack tip mean normal stress $\sigma(\mathrm{x}=$ 0) during EAC after different pre-cracking regimes (Fig. 5a) are practically insensitive to the cyclic load level $\mathrm{K}_{\max }$. Stresses in the interior at $x>0$ must be irrelevant for LAD since it is a surface dissolution reaction. Therefore, no difference should be expected for LAD from the residual stresses produced at different $\mathrm{K}$.

Toughening effect of the pre-cracking on LAD-driven EAC may be associated with accelerated dissolution of the cyclic plastic zone due to the inherently higher chemical activity of its damaged crystalline structure [2]. Due to cyclic damage accumulation not only ahead of the tip but also aside of the main crack path (Fig. 3), lateral strain-enhanced dissolution may allow chemical crack blunting to compete with dissolution-induced crack extension. Then, fracture load must increase together with the LAD-driven crack blunting. The LAD process may be supposed to involve a domain with a cumulative plastic strain above a certain level. This region must be proportional to the zone of accumulated cyclic plastic strain $\Delta \mathrm{x}_{\mathrm{Y}}$, or probably to the active plastic size $\mathrm{x}_{\mathrm{APZ}}$. Fig. $5 \mathrm{~b}$ displays this correspondence according to the EAC tests and numerical data about plastic zones.
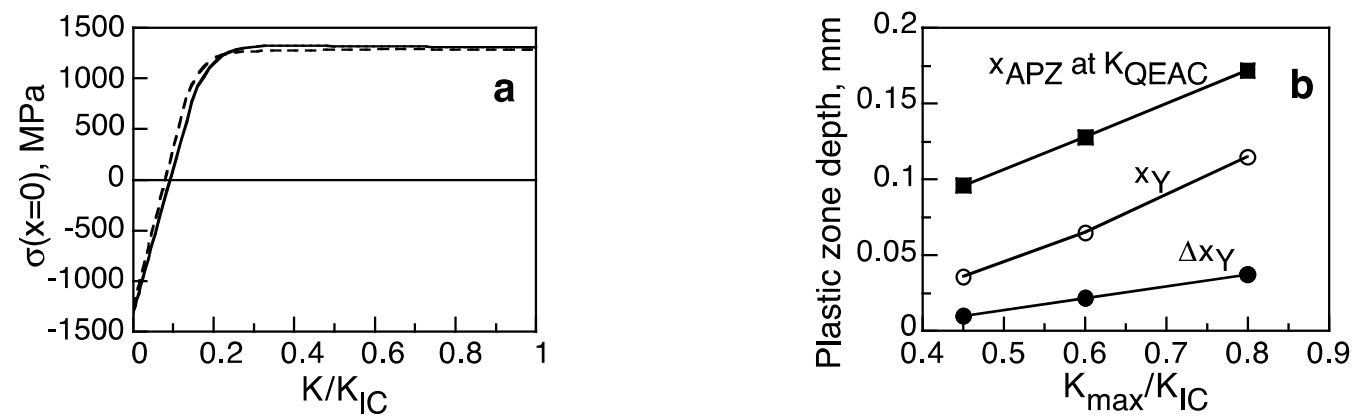

Figure 5: Mechanical factors of the crack growth by LAD: (a) evolutions of the crack tip hydrostatic stress $\sigma$ during EAC test after fatigue pre-cracking at $\mathrm{K}_{\max } / \mathrm{K}_{\mathrm{IC}}=0.45$ (dashed line) and 0.80 (solid line); (b) sizes of the plastic zones associated with EAC tests: the terminal active plastic zone during the LAD test ( $\mathrm{x}_{\mathrm{APZ}}$ at $\left.\mathrm{K}_{\mathrm{QEAC}}\right)$ which surpasses the cyclic and the monotonic plastic zones created during fatigue pre-cracking of the specimens, $\Delta \mathrm{x}_{\mathrm{Y}}\left(\mathrm{K}_{\max }\right)$ and $\mathrm{x}_{\mathrm{Y}}\left(\mathrm{K}_{\max }\right)$ respectively.

For HAC-controlled fracture, hydrogen transport to prospective rupture sites ahead of the crack tip may be supplied by two different mechanisms [8,9]: (i) sweeping by moving dislocations within the active plastic zone during load rise; (ii) diffusion in metal driven by hydrostatic stress gradient $\nabla \sigma$ towards the maximum tensile stress locations.

With regard to the first, hydrogenation and hydrogen damage area must be about as extensive as the active plastic zone. However, experimental data on the TTS width $\mathrm{x}_{\text {TTS }}$ as an indicator of hydrogen damage (Fig. 2) do not agree with calculated plasticity extent $\mathrm{x}_{\mathrm{APZ}}$ after different pre-cracking regimes (Fig. 6a). Although TTS overpassing the plastic zone size at lower $\mathrm{K}_{\max }$ levels in Fig. $6 \mathrm{a}$ may be attributed to the subcritical crack growth and plastic (damage) zone displacement next to the crack tip, it cannot be at $\mathrm{K}_{\max }=0.8 \mathrm{~K}_{\mathrm{IC}}$ when $\mathrm{x}_{\mathrm{TTS}}<<\mathrm{x}_{\mathrm{APZ}}$ even for stationary crack. This fact indicates that dislocational transport of hydrogen to rupture sites must not be the responsible for HAC in this case.

Considering stress-assisted diffusion, the near tip distributions of the hydrostatic stress $\sigma(\mathrm{x})$ displayed in Fig. 4 indicate that, during the rising load EAC tests, initially compressive stresses $\sigma(\mathrm{x})<0$ and accompanying negative gradients $\mathrm{d} \sigma / \mathrm{dx}$ $<0$ induced by fatigue pre-cracking delay hydrogen penetration towards rupture sites, and this effect is more pronounced for the heaviest fatigue regimes (i.e., with the highest $\mathrm{K}_{\max }$ ). This is supported by comparison of the evolutions of the average value of the stress gradient $\langle\nabla \sigma\rangle$ over the range $0<\mathrm{x}<\mathrm{x}_{\sigma+}\left(\mathrm{K}_{\mathrm{QEAC}}\right.$ ) (Fig. 6b) which delays hydrogen transportation into the metal as far as the respective component of the diffusion flux is $\mathbf{J}_{\sigma}$ proportional to $\nabla \sigma[8,9]$. This scale of averaging $\mathrm{x}_{\sigma+}\left(\mathrm{K}_{\mathrm{QEAC}}\right)$ corresponds to the maximum tensile stress position and possible location of the stress- 
controlled microfracture at hydrogen induced failure in experiments. For the precracking regimes compared in Fig. 6, this distance is fairly the same $\mathrm{x}_{\sigma+}\left(\mathrm{K}_{\mathrm{QEAC}}\right)=8 \mu \mathrm{m}$, so that it may be supposed to be a characteristic microstructural scale for HAC. Therefore, the heaviest fatigue pre-cracking regimes delay the hydrogen accumulation, and thus the progress of hydrogen degradation in the course of a rising load EAC test.
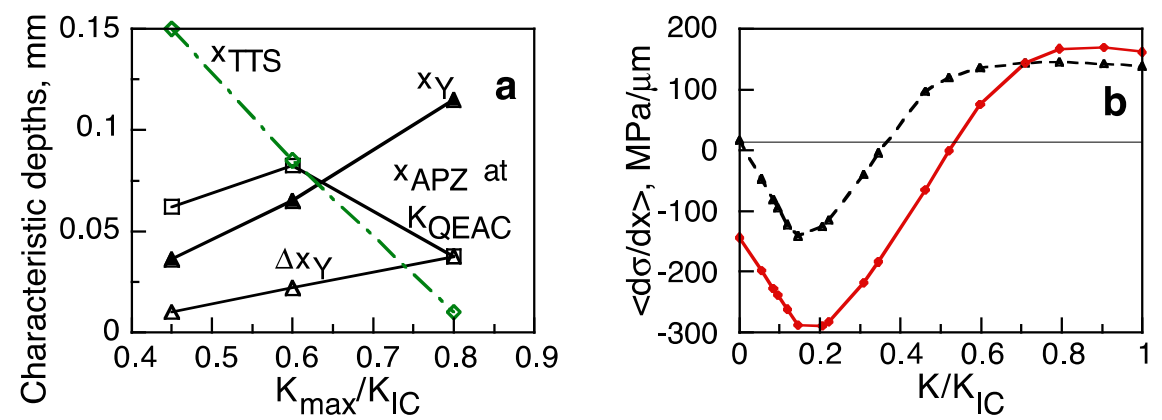

Figure 6: Mechanical factors of the crack growth by HAC: (a) comparison of the TTS extension and the plastic zones associated with HAC tests: at lower $K_{\max }-$ levels, the terminal active plastic zone (open square points) at the end of the HAC test ( $x_{A P Z}$ at $\left.K_{Q E A C}\right)$ surpasses the cyclic and the monotonic plastic zones created during fatigue precracking (triangles), $\Delta \mathrm{x}_{\mathrm{Y}}\left(\mathrm{K}_{\max }\right)$ and $\mathrm{x}_{\mathrm{Y}}\left(\mathrm{K}_{\max }\right)$ respectively; (b) evolutions of the average value of the hydrostatic stress gradient during HAC tests after fatigue pre-cracking at $\mathrm{K}_{\max } / \mathrm{K}_{\mathrm{IC}}=0.45$ (dashed line) and 0.80 (solid line).

\section{CONCLUSIONS}

$\mathrm{E}$ nvironmentally assisted cracking (EAC) of high-strength steel is clearly influenced by fatigue pre-cracking, since cyclic loading affects plastic strains and creates compressive residual stresses in the vicinity of the crack tip. Cyclic accumulation of plastic strain and compressive residual stresses improve the EAC behavior through increase of the failure load in aggressive environment either by:

(i) Chemical blunting of the crack tip enhanced by accumulated plastic strain in the near-tip area in the case of EAC in the anodic regime of localized anodic dissolution (LAD)

(ii) Delay of hydrogen supply to the fracture process zone near the crack tip by stress-assisted diffusion in the case of EAC in the cathodic regime of hydrogen assisted cracking (HAC).

\section{ACKNOWLEDGEMENTS}

7 he authors wish to acknowledge the financial support provided by the following Spanish Institutions: Ministry for Science and Technology (MCYT; Grant MAT2002-01831), Ministry for Education and Science (MEC; Grant BIA2005-08965), Ministry for Science and Innovation (MICINN; Grants BIA2008-06810, and BIA2011-27870) and Junta de Castilla y León (JCyL; Grants SA067A05, SA111A07, and SA039A08).

\section{REFERENCES}

[1] Toribio, J., Lancha, A.M., Overload retardation effects on stress corrosion behaviour of prestressing steel, Constr. Building Mater., 10 (1996) 501-505.

[2] Ford, F.P., Stress corrosion cracking of iron-base alloys in aqueous environments, in: C.L. Briant, S.K. Banerij (Eds.), Treatise on Materials Science and Technology, Embrittlement of Engineering Alloys, Academic Press, New York, 25 (1983) 235-274.

[3] Toribio, J., Lancha, A.M., Elices, M., Characteristics of the new tearing topography surface, Scripta Metall. Mater., 25 (1991) 2239-2244. 
[4] Toribio, J., Lancha, A.M., Effect of cold drawing on susceptibility to hydrogen embrittlement of prestressing steel, Mater. Struct., 26 (1993) 30-37.

[5] Rice, J.R., Mechanics of crack tip deformation and extension by fatigue, in: Fatigue Crack Propagation, ASTM STP 41, American Society for Testing and Materials, Philadelphia, (1967) 247-309.

[6] Kanninen, M.F., Popelar, C.H., Advanced Fracture Mechanics, Oxford University Press, New York, (1985).

[7] Handerhan, K.J., Garrison, W.M., Jr., A study of crack tip blunting and the influence of blunting behavior on the fracture toughness of ultra high strength steels, Acta Metall. Mater., 40 (1992) 1337-1355.

[8] Van Leeuwen, H.-P., The kinetics of hydrogen embrittlement: a quantitative diffusion model, Engng. Fract. Mech., 6 (1974) 141-161.

[9] Toribio, J., Kharin, V., K-dominance condition in hydrogen assisted cracking: the role of the far field, Fatigue Fract. Engng. Mater. Struct., 20 (1997) 729-745. 